\title{
PHYSICAL AND MATHEMATICAL MODELS OF TARGET COMPONENT EXTRACTION FROM RECTLINEAR CAPILLARIES
}

\author{
Jaroslav Gumnitsky ${ }^{1}$, Lubov Venger ${ }^{1}$, Vira Sabadash ${ }^{1} \bowtie$, Dmytro Symak ${ }^{1}$, \\ Anna Hyvlud ${ }^{1}$, Zoriana Gnativ ${ }^{1}$
}

https://doi.org/10.23939/chcht16.01.112

\begin{abstract}
The extraction of the solid component from the rectilinear capillary has been investigated. The presence of two extraction zones (convective and molecular diffusion) was confirmed. The effect of the system vacuumizing on the extraction rate has been studied. The convection zone during vacuumizing was found to be increased due to the appearance of the vapor phase bubbles. The mass transfer coefficients for the convective zone have been determined. A mathematical model of the molecular diffusion stage is given, taking into account the nonlinear change in the component concentration in the liquid due to the displacement of the extraction boundary. The molecular diffusion coefficients in the capillary have been determined.
\end{abstract}

Keywords: extraction, capillary, mathematical model, mass transfer coefficient, molecular diffusion coefficient.

\section{Introduction}

The components extraction from porous bodies is widely used in the chemical, food, pharmaceutical, hydrometallurgical industries, and this issue is reflected in a number of scientific publications. The process is relevant from the environmental standpoint, when large areas of soil are to be treated from inorganic and organic contaminants. Soil is the solid porous particles, the pores of which may contain liquid contaminants (e.g., oil and its derivatives) and solids (pesticides, heavy metals, salts). The peculiarity of extraction from porous bodies is the fact that the pore diameter of the solid phase is so small that the mass transfer in the pores occurs mainly due to the molecular diffusion.

According to the literature, the regularities of extraction are identical and described by the same kinetic dependences, similar equipment and methods of intensification. ${ }^{1}$ There are three parameters that have the

\footnotetext{
${ }^{1}$ Lviv Polytechnic National University

12, S.Bandery St., 79013 Lviv, Ukraine

virasabadash@gmail.com

(c) Gumnitsky, J.; Venger, L.; Sabadash, V.; Symak, D., Hyvlud, A.; Hnativ, Z., 2022
}

greatest impact on the extraction process. This is the structure of the inert skeleton from which the valuable component is extracted and the component to be extracted. The third component is the extractant, the main requirement for which is the high solubility of the component in it and the possibility of easy separation of the system extractant - extracted component. ${ }^{2}$

The structure of the inert skeleton significantly affects the transport of the component extracted from the solid phase to the volume of the liquid phase. First of all, the inert skeleton provides an isotropic or anisotropic distribution of the component. ${ }^{3,4}$ The solid skeleton may contain the component in a liquid or solid state. One of the characteristics of the inert phase is its porosity, which is created by individual capillaries. The size of the capillaries is determinative one. Depending on the capillary diameter, the following types are distinguished: macro-, meso- and microcapillaries. The presence of capillaries of different sizes affects the extraction process and particularly the process rate. In the presence of macropores, not only molecular diffusion but also convective mass transfer is possible. This phenomenon is described in works, ${ }^{5,6}$ where the regions near the capillary external surface, in which convective diffusion prevails over molecular one were detected. ${ }^{7}$ In mesopores, and especially in micropores, the transport of solid phase components occurs only due to the molecular diffusion and the main quantitative indicator is the internal molecular diffusion coefficient. ${ }^{8}$ Complex processes include extraction processes from plant raw materials, when the mass transfer of the useful component occurs in the cellular and intercellular media. A mathematical model of this process has been proposed and the kinetic constants that characterize this process have been determined. ${ }^{9,10}$

Any solid particle can be represented by a capillary-porous body, in which the inert skeleton forms a system of capillaries with the component to be extracted. The mechanism of the extraction process is as follows. During the contact of the solid particle with the liquid extractant, it seeps into the capillaries and dissolves the solid component. On the surface of the solid component 
that interacts with the liquid, the concentration is equal to the saturation concentration, which depends on the process temperature. So, it is necessary to establish the coefficient of internal diffusion of the component in the capillary, ${ }^{11}$ which determines the process rate. This value can be determined experimentally on the basis of a certain mathematical model. Mathematically, this problem belongs to the problems with the moving boundary of the solid-liquid interaction. ${ }^{12,13}$ Analytical solutions of such problems cause difficulties, so simplified mathematical models are used, on the basis of which the coefficient of internal diffusion of the extracted component in the capillary is determined. This method was used by Gumnitskii et $a l^{6}$ The method involved a rectilinear distribution of concentrations in the capillary. The internal diffusion coefficient $D$ was determined from Eq. (1):

$$
\frac{l^{2}}{t}=\frac{2 D^{*}\left(C_{S}-C_{1}\right)}{\rho_{S}}
$$

where $l$ is the length of the solubility zone, $\mathrm{m} ; t$ is time, $\mathrm{s}$; $C_{S}$ and $C_{1}$ are the saturation concentration and the component concentration on the capillary external surface, respectively, $\mathrm{kg} / \mathrm{m}^{3} ; \rho_{S}$ is the density of the solid phase, $\mathrm{kg} / \mathrm{m}^{3}$.

The research was aimed to propose the intensification of extraction from the solid phase, ${ }^{13}$ to identify regions of convective and molecular diffusion during the extraction from rectilinear capillaries and to investigate the possibility of the process intensification using the system vacuumizing and creating boiling conditions for the extractant.

The aim of this work is to experimentally determine the mass transfer coefficient for the convective diffusion section and to create a mathematical model for the extraction from a part of the capillary under the conditions of molecular diffusion with a moving solubility limit and nonlinear concentration distribution.

\section{Experimental}

\subsection{Experimental Setup}

The experimental setup is represented in Fig. 1. The setup provides a number of elementary processes that must be implemented during the extraction process from a single capillary when a liquid is boiled under vacuum. It was necessary to visually monitor the displacement of the solid solubility limit in the capillary, to create the necessary vacuum, to determine and maintain the required temperature in the apparatus, to determine the amount of vapor phase which stirs the liquid. The presence of a magnetic stirrer allowed stirring the liquid without vaporization and thus creating the identical hydrodynamic conditions in the liquid phase.

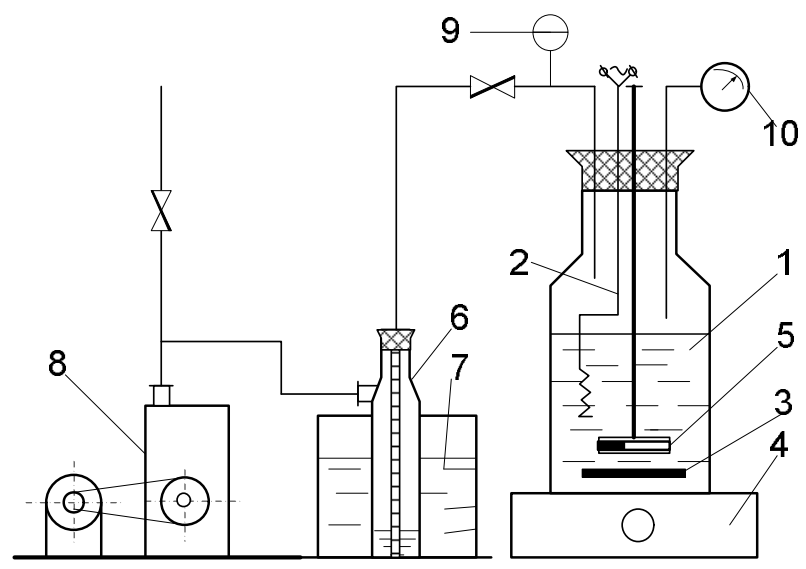

Fig. 1. Scheme of experimental setup: glass extractor (1); electric heating (2); magnetic stirrer (3); drive of the magnetic stirrer (4); capillary with the studied component (5); condenserflowmeter (6); cooling solution (7); vacuum pump (8); vacuum gauge (9) and thermometer (10)

The main part of the setup is the extractor 1, equipped with the electric heating 2 , which provides a constant temperature of the liquid in the extractor. Mechanical stirring of the liquid in the extractor is carried out by a magnetic stirrer consisting of a magnet 3 and a drive 4 . The capillary 5 fixed on the solid rod can move vertically. Extractor 1 is connected to a condenserflowmeter 6 , immersed in cold water in a tank 7 . The extractor 1 is connected to the vacuum pump 8 through the condenser-flowmeter 6 . The vacuum in the reactor was measured by a vacuum gauge 9 , and the temperature by a thermometer 10 . Water vapor from the reactor was condensed in the condenser-flowmeter 6 . and allowed to determine the intensity of vaporization. The experiments were performed at the same temperature of $343 \mathrm{~K}$.

\subsection{Experimental Procedure}

The procedure was as follows. The liquid was poured into the extractor 1 . A capillary mounted on a metal rod was installed above the surface of the liquid. The liquid was heated by the electric heating and stirred with a magnetic stirrer. After reaching the set temperature, the capillary rod was immersed in the liquid and the time of the extraction process beginning was recorded. The length of the region released from the extracted component was recorded with a reference microscope. At the temperature of $343 \mathrm{~K}$ the absolute pressure in the system was $3.12 \cdot 10^{4} \mathrm{~Pa}$. A similar extraction of the component from the capillary was performed at vacuum under which the liquid boils.

Model rectilinear capillaries with a hole diameter of $0.8 \mathrm{~mm}$ were used in the experiments. The capillaries were filled with potassium chloride, the density of which was $1980 \mathrm{~kg} / \mathrm{m}^{3}$. Stuffing of capillaries did not allow to 
reach salt integrity. For example, one of the samples showed a density of $1742 \mathrm{~kg} / \mathrm{m}^{3}$, which corresponds to a porosity of 0.129 . Density of the component of each capillary was determined before the extraction, because their value was taken into account for mathematical modeling of the extraction process. Using a reference microscope the displacement of solubility limit of the solid $v s$. time was determined during the extraction under mechanical stirring and under vacuum.

\section{Results and Discussion}

\subsection{Interpretation of Experimental Results}

Fig. 2 shows the experimentally obtained values of the displacement zones of potassium chloride solubility limit in a straight capillary during the extraction under mechanical stirring and vaccumizing the system. The extraction temperature of $343 \mathrm{~K}$ allows to exclude the temperature factor from the analysis and to compare only the hydrodynamics. In both cases, two zones are clearly distinguished. In the initial time intervals $(0-150 \mathrm{~s})$ there is a rapid displacement of the extraction boundary, which is possible only in the region of convective diffusion. A comparison of mechanical stirring and vacuum method shows that vacuumizing significantly expands the convection zone. For capillaries with a displacement zone length up to $10 \mathrm{~mm}$ (zone B), the extraction occurs with a higher intensity. The second one is a zone of molecular diffusion (zone A), which is characterized by a slow displacement of the extraction zone. This zone begins after $100-150 \mathrm{~s}$ for mechanical mixing and $150-200 \mathrm{~s}$ for vacuum conditions. In the time interval between convective and molecular diffusion there is a transition zone. Studies have shown that the vertical and horizontal placements of capillaries slightly affect the extraction kinetics (Fig. 3). Similar results with the presence of two zones (convective and molecular) were obtained during the study of copper sulfate extraction from a single capillary. ${ }^{14}$ Similar phenomenon is observed during adsorption processes. For example, when studying the kinetics of copper ions adsorption by a natural zeolite, one can observe an external diffusion region in the initial stages, which further turns into the intradiffusion one. ${ }^{15}$

The physical interpretation of capillary extraction processes is shown in Fig. 3, which schematically shows the distribution of concentrations of the extracted component in the convective and molecular-diffusion regions. The convective part is near the capillary hole and its length is equal to $l_{k}$. The extraction zone did not reach $l_{k}$ (Fig. 3a). The distribution of the extracted component concentrations is typical of the convective zone.

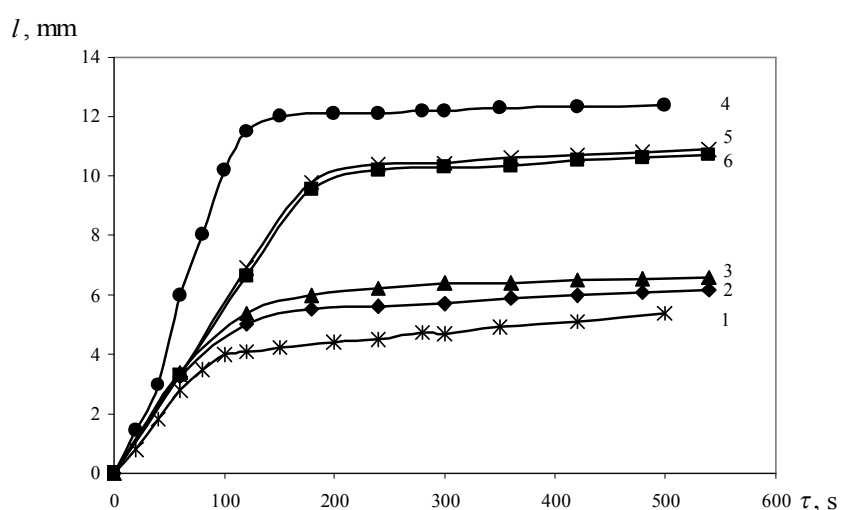

Fig. 2. The displacement of the extraction zone boundaries depending on the process time: extraction under mechanical stirring (1-3); extraction under vacuumizing the system with a boiling liquid (4-6). For 1, 4 there is a horizontal position of the capillary; for 2, 6 the extraction zone is directed upwards; for 3, 5 the extraction zone is directed downwards

a)

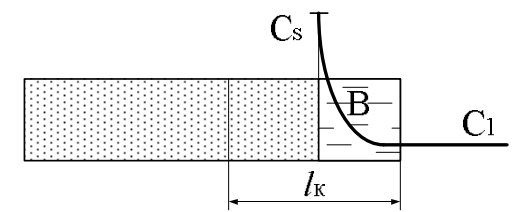

b)

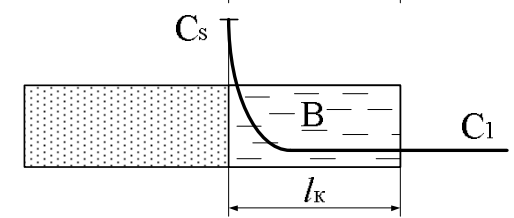

c)

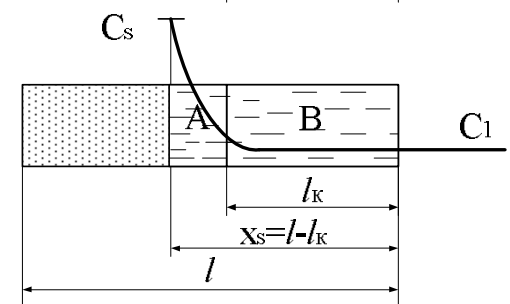

Fig. 3. Physical representation of convective and moleculardiffusion extraction from a single capillary: the extraction occurs in the convective zone and the solid-liquid phase boundary is smaller than that of the convection zone (a); the extraction has reached the convection zone (b); the extraction occurs in the zone of molecular diffusion (c)

On the surface of the solid phase, the concentration is equal to the saturation concentration (solubility) $C_{S}$. A boundary diffusion layer is formed near the solid surface, which is typical of convective-diffusion processes. The concentration in the layer decreases to the concentration in the volume of liquid $C_{1}$, which is equalized in the volume of liquid and capillary space to length $l_{k}$ due to the stirring (Fig. 3b). After dissolving and extracting the component from the part of the capillary of length $l_{k}$, the process takes place in the region $x_{s}>l_{k}$, in which there are no turbulent 
pulsations, and the mass transfer is provided by a molecular diffusion. The distribution of concentrations is shown in Fig. 3c. No boundary layer is observed and the concentration of dissolved component decreases from the saturation concentration $C_{S}$ to the concentration $C_{1}$. This transition is often represented as a straight line, although the process with a moving phase boundary, where the change in concentrations is nonlinear, occurs as well. This must be taken into account for the mathematical description of the process. The theoretical analysis of the process and its analytical confirmation are given below. Two stages of extraction are considered: a convective diffusion and a molecular-diffusion stage.

\subsection{Mass Transfer in the Region of Convective Diffusion}

The dissolution intensity in the region of convective (turbulent) diffusion, which lies in the region of the capillary length $0-l_{k}$, is determined by the mass transfer equation, which includes the mass transfer coefficient $\beta$, determining the intensity of this process:

$$
M=\beta \cdot F \cdot\left(C_{S}-C\right) \tau
$$

where $M$ is the mass of the extracted component, $\mathrm{kg} ; F$ is the surface area of the extraction, $\mathrm{m}^{2} ; C_{s}$ and $C$ are the saturation and running concentrations, respectively, $\mathrm{kg} / \mathrm{m}^{3}$.

The mass $M$ was determined as follows:

$$
M=F \cdot l \cdot \rho_{S}
$$

where $l$ is the length of the convection zone, $\mathrm{m} ; \rho_{S}$ is the density of the solid phase, $\mathrm{kg} / \mathrm{m}^{3}$.

The determined value of the mass transfer coefficient $\beta$ for extraction under mechanical mixing and horizontal position of the capillary is $1.78 \cdot 10^{-4} \mathrm{~m} / \mathrm{s}$; for vacuum conditions it is $3.55 \cdot 10^{-4} \mathrm{~m} / \mathrm{s}$. The values of the mass transfer coefficient are characteristic of externally diffusion mass transfer processes. ${ }^{5,6}$

For the vertical position of the capillary during mechanical mixing of the liquid, the values of $\beta$ were: $2.466 \cdot 10^{-4} \mathrm{~m} / \mathrm{s}$ (a capillary was open from above) and $2.6 \cdot 10^{-4} \mathrm{~m} / \mathrm{s}$ (a capillary was open from below). For vacuum conditions for vertically fixed capillaries, the mass transfer coefficients are $2.5 \cdot 10^{-4}$ and $2.47 \cdot 10^{-4} \mathrm{~m} / \mathrm{s}$. The obtained values indicate the same hydrodynamic conditions, due to which the mass transfer coefficients are close in their values. The arithmetic mean value of the coefficient is $2.51 \cdot 10^{-4} \mathrm{~m} / \mathrm{s}$, and the maximum error is $1.75 \%$.

The presence of a turbulent diffusion zone in the capillaries significantly accelerates the extraction process. The appeared vapor phase stirs the liquid, reducing the boundary diffusion layer near the dissolution surface in the capillary. At the same time, the high values of mass transfer coefficients differ slightly. Therefore, the main intensifying effect is caused by the displacement of extraction zones due to convection.

\subsection{Molecular-Diffusion Stage of Extraction}

After the ending of the turbulent diffusion stage, the reaching of the extraction zone $l_{k}$ and the transition to the zone $x_{s}>l_{k}$, the extraction process is determined by the molecular diffusion. On the surface of the solid phase in the capillary which is in contact with the liquid, the concentration of the component in the liquid is equal to the saturation concentration $C_{s}$. As can be seen from Fig. $3 \mathrm{~b}$, there is a smooth transition from the saturation concentration to the concentration in the turbulent zone $C_{1}$. The application of the extraction model in this zone is approximate because it does not take into account the displacement of the solubility limit. ${ }^{6}$ The method used by us is based on the balance ratios of the changes in the component mass over an infinitesimal period of time $d \tau$ in a rectilinear capillary on an infinitesimal section. The capillary is filled with a solid component to be extracted. The solid component consists of individual particles and its volumetric fraction is equal to $\varepsilon$. The space between the particles during the extraction is filled with a liquid extractant and its volumetric fraction is $(1-\varepsilon)$. It is obvious that during the extraction the extractant will dissolve the solid phase and its concentration will be equal to the saturation concentration of this component $C_{S}$. The scheme of such rectilinear capillary is shown in Fig. 3c. The crosshatched region represents the solid phase to be dissolved and extracted. Zone $\mathrm{A}$ is the region of a component transferred by a molecular diffusion, zone B is the region of convective diffusion. The phenomenon of convective diffusion is observed near the external surface in many cases of extraction. The zone $l_{k}$ is insignificant and is clearly observed during the experiments. The extraction time is determined by the molecular-diffusion zone, which determines the required extraction time. In the convective zone, the liquid is stirred and the component concentration is equal to the concentration in the volume of liquid surrounding the particle. This concentration is denoted as $C_{1}$.

In zone $\mathrm{A}$, the component is transferred by the molecular diffusion. The differential equation that describes the nonstationary process of one-dimensional diffusion in a capillary has the view:

$$
\frac{\partial C_{2}}{\partial \tau}=D^{*} \frac{\partial^{2} C_{2}}{\partial x^{2}}
$$

where $C_{2}$ is the running concentration in zone $\mathrm{A}, \mathrm{m} ; \mathrm{D} *$ is the molecular diffusion coefficient in the capillary, $\mathrm{m}^{2} / \mathrm{s}$.

Eq. (4) is supplemented by the equation of material balance, which takes into account the movement of the 
dissolution zone. The material balance at the solubility limit can be recorded as Eq. (5):

$$
\begin{aligned}
& \frac{d}{d \tau}\left[F\left(L-x_{S}\right) \rho_{n}+\int_{L-x_{S}}^{L} F C_{2} d x\right] d \tau= \\
& =-F D^{*}\left(\frac{\partial C_{2}}{\partial x}\right)_{x=L} d \tau-F C_{1} \varepsilon\left(\frac{d x_{S}}{d \tau}\right) d \tau
\end{aligned}
$$

The left side of Eq. (5) is the mass of the extracted component in the solid phase on the section $\left(L-x_{S}\right)$ and in the volume of the liquid phase $F \cdot x_{S}$. The right part represents the mass of the component leaving the diffusion region and the mass coming to the capillary from the outside with the concentration of the component in the volume of liquid $C_{1}$. The concentration of $C_{2}$ is a running component in the molecular diffusion region. After reduction and regrouping, Eq. (5) can be written:

$$
\frac{d x_{S}}{d \tau}\left(\varepsilon \cdot C_{1}+\rho_{n}\right)-\frac{d}{d \tau} \int_{L-x_{S}}^{L} C_{2} d x=-D\left(\frac{\partial C_{2}}{\partial x}\right)_{x=L}
$$

The boundary conditions for molecular diffusion at the boundaries of zone A have the view:

$$
\left\{\begin{array}{l}
C_{2}\left(l_{k}, \tau\right)=C_{1} \\
C_{2}\left[\left(l-l_{k}\right), \tau\right]=C_{S} \\
\frac{\partial^{2} C_{2}}{\partial x^{2}}=0 \\
\frac{\partial^{2} C_{2}}{\partial x^{2}}{ }_{\mid x=l-l l_{k}}=0
\end{array}\right.
$$

The function corresponding to the boundary conditions is obtained by solving the third and fourth equations of the system (7) and is similar to the boundary conditions of thermal conductivity: ${ }^{1}$

$$
C_{2}=\frac{C_{S}-C_{1}}{l-l_{k}}(l-x)+C_{1}
$$

Taking into account the boundary conditions (7) and (8), Eq. (6) has a view:

$$
\frac{d x_{S}}{d \tau}\left(\varepsilon \cdot C_{1}+\rho_{n}-\frac{\Delta C}{2}-C_{1}\right)=D^{*} \frac{\Delta C}{x_{S}}
$$

where $\Delta C=C_{S}-C_{1}$.

After performing certain transformations, we obtain a differential equation:

$$
\int_{0}^{x_{S}} x_{S} \cdot d x=\frac{\Delta C}{\left[\varepsilon \cdot C_{1}+\rho_{n}-\frac{1}{2}\left(C_{S}+C_{1}\right)\right]} \cdot D^{*} \int_{0}^{\tau} d \tau
$$

Integrating Eq. (10) within the specified limits, we obtain:

$$
\frac{x_{S}^{2}}{2 D^{*} \tau}=\frac{\Delta C}{\varepsilon \cdot C_{1}+\rho_{n}-0.5\left(C_{S}+C_{1}\right)}
$$

Theoretically obtained Eq. (11) may be used to determine the internal diffusion coefficient $D^{*}$. Moreover, the nonlinearity of the concentration caused by the moving phase boundary is taken into account. Eq. (1) assumes that the linear distribution of concentrations in the capillary is approximate. Taking into account that the monolithic capillary packing was not achieved in the above experiments, it is necessary to consider the share of a solid phase $\varepsilon$ in Eq. (1). Bringing the specified dependence in the left part of Eq. (1) to a similar expression in Eq. (11) and taking into account the value of $\varepsilon$, we obtain:

$$
\frac{x_{S}^{2}}{2 D^{*} \tau}=\frac{\Delta C}{\rho_{n}-C_{S}(1-\varepsilon)}
$$

The values of $\frac{x_{S}^{2}}{2 D^{*} \tau}$ were compared for the approximate solution obtained from the theory of rectilinear concentrations distribution (12) and for the exact solution (11).

For experimental studies, the values of $\frac{x_{S}^{2}}{2 D^{*} \tau}$ for approximate $A_{1}$ (12) and exact $A_{2}(11)$ solutions were determined. For experimental conditions $\Delta C=300 \mathrm{~kg} / \mathrm{m}^{3}$; the density of filling the capillary with the solid phase $\rho_{n}=$ $1742 \mathrm{~kg} / \mathrm{m}^{3} ; \varepsilon=0.871 ; A_{1}=0.1761 ; A_{2}=0.1884$. The error for $A_{1}$ and $A_{2}$ was $6.9 \%$.

The determined value of the internal diffusion coefficient $D^{*}$ for different positions of the capillary and approximate and exact theories are:

$$
\begin{aligned}
& \text { 1) approximate theory } \\
& \text { - vertical position } D^{*}=9.82 \cdot 10^{-9} \mathrm{~m}^{2} / \mathrm{s} \text {; } \\
& \text { - horizontal position } D^{*}=1.768 \cdot 10^{-8} \mathrm{~m}^{2} / \mathrm{s} \text {; } \\
& \text { 2) exact theory } \\
& \text { - vertical position } D^{*}=9.3 \cdot 10^{-9} \mathrm{~m}^{2} / \mathrm{s} \text {; } \\
& \text { - horizontal position } D^{*}=1.674 \cdot 10^{-8} \mathrm{~m}^{2} / \mathrm{s} \text {. }
\end{aligned}
$$

\section{Conclusions}

The obtained results indicate the presence of two mechanisms of extraction from rectilinear capillaries with a diameter of $0.8 \mathrm{~mm}$ : the convective one at the beginning of the capillary and the molecular-diffusion one after the convective zone. The length of the convective zone for capillaries of this diameter depends on the intensity of the hydrodynamic impact on the system. Vacuumizing the system allows to increase the convection zone without affecting the mass transfer coefficient. Two zones of extraction of the solid component from rectilinear capillaries (convective and molecular-diffusion) were found. Owing to the vapor phase formation the system vacuumizing allows to increase the convective zone due to the influence of the vapor phase on the liquid in the capillary. The mass transfer coefficients inside the capillary were experimentally determined and their 
independence from the type of stirring was shown. A mathematical model of molecular diffusion based on the use of balance relations, according to which the obtained concentration profile is nonlinear due to the moving phase boundary, was proposed. The internal diffusion coefficients for this model were determined and their discrepancy with the corresponding coefficients of rectilinear distribution concentrations model was shown.

\section{References}

[1] Romankov, P.G.; Frolov, V.F.; Flisyuk, O.M. Massoobmennyie Processy Khimicheskoy Tekhnologii; Khimizdat: Sankt-Peterburg, 2020. [2] Kurt, S.K.; Gürsel, I.V.; Hessel, V.; Nigam, K.D.P.; Kockmann, N. Liquid-Liquid Extraction System with Microstructured Coiled Flow Inverter and Other Capillary Setups for Single-Stage Extraction Applications. Chem. Eng. J. 2016, 284, 764-777. https://doi.org/10.1016/j.cej.2015.08.099

[3] Vakinti, M.; Mela, S.-M.; Fernández, E.; Psillakis, E.; Psillakis, E. Room Temperature and Sensitive Determination of Haloanisoles in

Wine Using Vacuum-Assisted Headspace Solid-Phase

Microextraction. J. Chromatogr. 2019, 1602, 142-149.

https://doi.org/10.1016/j.chroma.2019.03.047

[4] Mascrez, S.; Psillakis, E.; Purcaro, G. A Multifaceted Investigation on the Effect of Vacuum on the Headspace Solid-Phase

Microextraction of Extra-Virgin Olive Oil. Anal. Chim. Acta 2020,

1103, 106-114. https://doi.org/10.1016/j.aca.2019.12.053

[5] Aksel'rud, G.A.; Gumnitskii, Y.M. Some Characteristics of the Kinetics of Ion Exchange in the Case of Pulsating Motion of a Liquid. J. Eng. Phys. 1970, 19, 1024-1026.

https://doi.org/10.1007/BF00828782

[6] Gumnitskii Y.M.; Sen'kiv V.N. Extraction of a Solid Substance from Linear Capillaries During Periodic Boiling under Vacuum.

Theor. Found. Chem. Eng. 2006, 40, 253-258.

https://doi.org/10.1134/S0040579506030055

[7] Symak, D.; Atamanyuk, V.; Gumnitsky, J. Analysis of Dissolution Kinetics based on the Local Isotropic Turbulence Theory. Chem.

Chem. Technol. 2015, 9, 493-496.

https://doi.org/10.23939/chcht09.04.493

[8] Symak, D.; Gumnitsky, J.; Atamaniuk, V.; Nagurskyy, O. Investigation of Physical Dissolution of Benzoic Acid Polydisperse Mixture. Chem. Chem. Technol. 2017, 11, 469.

https://doi.org/10.23939/chcht11.04.469

[9] Pavliuk, I.; Dyachok, V.; Novikov, V.; Ilkiv, N. Kinetics of Biologically Active Compound Extraction from Hops Strobiles Extraction Cake. Chem. Chem. Technol. 2017, 11, 487-491. https://oi.org/10.23939/chcht11.04.487
[10] Dyachok, V.; Ilkiv, I. On the Mechanism of Extraction from Solid Bodies of Cellular Structure. Chem. Chem. Technol. 2013, 7, 27-30. https://doi.org/10.23939/chcht07.01.027

[11] Sattari-Najafabadi, M.; Esfahany, M.N.; Wu, Z., Sunden, B. Mass Transfer between Phases in Microchannels: A Review. Chem. Eng. Process 2018, 127, 213-237. https://doi.org/10.1016/j.cep.2018.03.012

[12] Vorobyova, V.I.; Skiba, M.I.; Trus, I.M. Apricot Pomaces Extract (Prunus Armeniaca L.) as a Highly Efficient Sustainable Corrosion Inhibitor for Mild Steel in Sodium Chloride Solution. Int. J. Corros. Scale Inhib. 2019, 8, 1060-1083. https://doi.org/10.17675/2305-6894-2019-8-4-15

[13] Allaf, T.; Tomao, V.; Besombes, C.; Chemat, F. Thermal and Mechanical Intensification of Essential Oil Extraction from Orange Peel via Instant Autovaporization. Chem. Eng. Process. 2013, 72, $24-$ 30. https://doi.org/10.1016/j.cep.2013.06.005

[14]. Beiranvand, M.; Ghiasvand, A. Simple, Low-Cost and Reliable Device for Vacuum-Assisted Headspace Solid-Phase Microextraction of Volatile and Semivolatile Compounds from Complex Solid Samples. Chromatographia 2017, 80, 1771-1780.

https://doi.org/10.1007/s10337-017-3422-z

[15] Sabadash, V.; Mylanyk, O.; Matsuska, O.; Gumnitsky, J. Kinetic Regularities of Copper Ions Adsorption by Natural Zeolite. Chem. Chem. Technol. 2017, 11, 459-462.

https://doi.org/10.23939/chcht11.04.459

Received: June 22, 2020 / Revised: August 01, 2020 / Accepted: October 12, 2020

\section{ФІЗИКО-МАТЕМАТИЧНА МОДЕЛЬ ЕКСТРАГУВАННЯ ЦІЛЬОВОГО КОМПОНЕНТА З ПРЯМОЛІНІЙНИХ КАПІЛЯРІВ}

Анотація. Досліджено екстрагування твердого компонента з прямолінійного капіляра. Підтверджено наявність двох зон екстрагування: конвективної та молекулярно-дифузійної. Досліджено вплив вакуумування системи на швидкість екстрагування. Показано збільшення зони конвекиії під час вакуумування внаслідок виникнення бульбашок пароподібної фази. Визначено коефіџієнти масовіддачі для конвективної зони. Наведено математичну модель молекулярно-дифузійної стадї з врахуванням нелінійної зміни концентрачї компонента y рідині внаслідок переміщення границі екстрагування. Визначено коефіцієнти молекулярної дифузії у капілярі.

Ключові слова: екстрагування, капіляр, математична модель, коефічієнт масовіддачі, коефіцієнт молекулярної дифузіï. 